Review

\title{
Compliance with Saliva Collection Protocol in Healthy Volunteers: Strategies for Managing Risk and Errors
}

\author{
Kashi Raj Bhattarai ${ }^{1}$, Hyung-Ryong Kim ${ }^{2}{ }^{\bowtie}$, Han-Jung Chae ${ }^{\circledR}$ \\ 1. Department of Pharmacology and Institute of New Drug Development, School of Medicine, Chonbuk National University, Jeonju, Republic of Korea; \\ 2. Graduate School, Daegu Gyeongbuk Institute of Science and Technology (DGIST), Daegu, 42988, Republic of Korea. \\ $\square$ Corresponding authors: Han-Jung Chae, hjchae@jbnu.ac.kr, Tel.: +82-63-270-4454; Hyung-Ryong Kim, hrkim@dgist.ac.kr, Tel: +82-53-785-2601 \\ ( ) Ivyspring International Publisher. This is an open access article distributed under the terms of the Creative Commons Attribution (CC BY-NC) license \\ (https://creativecommons.org/licenses/by-nc/4.0/). See http://ivyspring.com/terms for full terms and conditions.
}

Received: 2018.01.25; Accepted: 2018.04.14; Published: 2018.05.22

\begin{abstract}
Salivary bioscience technologies such as electrophoresis are widely applied for diagnosing systemic health status. Diagnosis using a saliva sample has emerged as a preferred technique since the sample is easy to collect and the method is inexpensive and non-invasive. Salivary diagnostics have even been identified as potential substitutes for serum protein biomarkers. However, the optimal protocol for collecting saliva has not yet been established. In many scientific settings, such as randomized controlled trials, sampling and statistical errors often occur when handling samples from healthy volunteers. These errors can be due to the psychological behavior of the volunteers, subject nonadherence, questionnaire characteristics, collection methods, and/or sample processing. The purpose of the review presented here is to outline the strategies for managing the risk factors and to minimize the sampling errors during saliva collection in healthy volunteers.
\end{abstract}

Key words: Saliva collection; healthy volunteers; salivary proteomics; psychological stress; sampling errors; risk management

\section{Introduction}

Saliva is an important specimen in dental research and in the oral physiology field due to its suitability as a non-invasive diagnostic tool. Saliva has been used to diagnose various autoimmune diseases, diabetes, cardiovascular diseases, dental caries, and other oral diseases [1-3]. Saliva volume and biochemical composition differ among individuals; these parameters are influenced by age [4], sex [5], and diet [6]. Age and salivary flow rate directly influence salivary alpha-amylase activity in healthy individuals [4]. Significantly less unstimulated whole saliva has been observed in unmedicated, denturewearing healthy females compared to their male counterparts [7]. Obtaining saliva is rapid, simple, and painless, making this sample an uncomplicated tool for disease screening [8]. However, sample collection must be appropriately optimized to reduce error [9]. For example, collection technique and collection duration can both affect cortisol and salivary amylase activity measurements [9]. Collection and processing methods also affect the measured total protein concentration, as well as C-reactive protein and immunoglobulin (IgA) concentrations [8]. Various factors such as assay methods and standards used affect the results obtained by salivary fluid assessment. For instance, saliva samples clarified by centrifugation show lower concentrations of lysozyme than their whole saliva counterparts. In addition, the lysoplate assay method has been shown to yield higher lysozyme concentrations than the turbidimetric assay [10]. Moreover, the rate of saliva secretion varies among healthy individuals. Since the volume differs among individuals, salivary flow rate and other salivary biomarkers differ from individual to individual. This review focuses on the saliva collection procedure, the factors contributing to error, and strategies for error management.

\section{Importance of salivary proteomics in biomedical technology}

Research based on saliva proteomics is currently 
emerging due to interest in identifying prognostic biomarkers for several physiological and pathological conditions. Salivary diagnostics facilitates the early detection and diagnosis of several hormone levels and oral diseases and is also used to differentiate normal control and systemic disease patients. More than 3000 proteins and peptides have been characterized using recent proteomic technologies in human saliva [11]. Different conditions and ailments such as oral inflammatory diseases, oral squamous cell carcinoma, periodontal diseases, diabetes mellitus, AIDS, hepatitis B and C, cystic fibrosis, and systemic sclerosis have been investigated in the salivary proteome [12]. Several salivary biomarkers for oral cancer diagnosis including CD44, CD59, p53 antibodies, M2BP (tumor antigen), MRP14, profilin, histone $\mathrm{H} 1$, moesin, involucrin, catalase, transferrin, salivary zinc finger, tobacco specific nitrosamines, keratin 36, and cystatin A have been investigated using different proteomic tools, which have been reviewed in previous articles [12-14]. Similarly, NF-kB-dependent cytokines and immunosuppressive cytokines such as IL-4, IL-10, IL-13, and IL-1RA have been identified as potential biomarkers of oral preneoplastic lesions and OSCC [15, 16]. Various salivary proteomes are present in inflammatory diseases; for example, Sjogren's syndrome includes lactoferrin, $\beta 2$-microglobulin, polymeric Ig receptor, lysozyme C, Ig kappa- light chain, cystatin C, carbonic anhydrase VI, and salivary amylase [17]. Similarly, salivary proteomics has also contributed to the early detection and understanding of neuro-psychiatry diseases, for example, autism, reduced cognition, and depression [18]. High technology proteomic tools including HPLC, ELISA, immunoblot, LC/MS, mass spectrometry, 2D electrophoresis, MS-based proteomics, MALDI-TOF MS technology, PCR, immuno-radiometric assay, and many more are being used to identify several biological markers [13].

\section{Sampling considerations}

\section{Sample collection requirements}

While saliva collection does not require extensive preparation, eligible participants need to receive appropriate instructions. Proper sample collection requires accurate participant identification, sufficient sample volume, and the appropriate type of container. Moreover, sample labeling and handling should be performed consistently.

\section{Selection based on age and gender}

Saliva is comprised of many components including water, electrolytes, enzymes, and antimicrobial agents. These components can vary or remain stable with age [19]. For example, salivary flow rate and calcium were observed to be decreased in elderly people compared with young individuals, whereas matrix metalloproteinase- 8 and collagenase type-1 levels were significantly increased with unaltered salivary alpha-amylase [19]. However, another previous report showed the significantly decreased alpha-amylase activity in elderly people and no changes in the secretion rates and salivary calcium levels [20]. Similarly, the significant difference in the mucin levels was found in the whole saliva of young and aged subjects [21]. Surprisingly, newborns and adults also exhibited the differences in the salivary protein profiles [22, 23]. The human salivary proteome such as salivary proline-rich proteins, peptide levels, acidic proline-rich phosphoproteins, histatins and cystatin $S$ has been investigated in the different age groups and found that the human salivary proteome displayed major variation in childhood and adolescence [23]. Likewise, a previous study observed high salivary flow rate in the healthy volunteers younger than 44 years [24]. The unstimulated saliva secretion was higher in healthy men when compared with women, where the author suggested that the salivary gland size have an effect on the salivary secretion since the size of salivary gland of female is smaller than men [24, 25], indicating gender-dependent secretion. Therefore, healthy volunteers from different age groups and gender should be categorized separately to limit statistical errors.

\section{Significance of mouth position during saliva collection}

The different pairs of salivary glands include parotid glands, submandibular glands, sublingual glands, and numerous minor salivary glands. While saliva secreted from these glands contains some common components, the concentrations can vary from one gland to another [26]. For example, the parotid glands contain large numbers of serous acinar cells and produce high levels of alpha-amylase and proline-rich proteins. While the submandibular glands secrete less alpha-amylase than the parotid glands, they secrete more mucins. The sublingual glands mainly consist of mucous cells and contain high concentrations of glycoproteins (mucins) and a large amount of lysozyme. Minor salivary glands mainly produce mucins and lipase [26].

Whole saliva is the mixture of saliva secreted in the oral cavity from various glands in addition to other components such as nasal and bronchial secretions, food debris, tears, bacteria, and gingival crevicular fluid [27]. In addition, saliva production, salivary components, and salivary origin depend on whether the individual is in the resting state or the 
stimulated state. For example, cortisol, alpha-amylase, and secretory IgA levels are affected by stimulation [26]. Investigators should consider that the production and composition of saliva from each gland are different and instruct individuals accordingly. Each individual should rigorously follow the literature concerning saliva collection techniques. This consistency in the collection method is important because it ensures high quality data.

\section{Measurement of salivary volume before the trial of interest in a placebo trial: Select only the intermediate scoring individuals}

To eliminate errors in clinical trials using saliva from healthy volunteers, collection procedures must be standardized. Saliva secretion varies between individuals. If the same individual collects saliva at different time points, various salivary flow rates will be obtained, thus hindering interpretation [28]. To minimize error, individuals secreting high volumes of saliva and individuals secreting low volumes should be excluded from the study, and only intermediate scoring participants should be included.

\section{Provide detailed information regarding the method of saliva collection}

Various methods are available for the collection of whole saliva. Common methods include the draining method, the spitting method, the suction method, and the swab method [27]. Similarly, several commercially available devices and methods can be used to collect saliva from individual glands [27]. Participants should receive proper guidance on how to best perform sample collection. It is strongly advised that only one type of collection device be used throughout a given study [29]. It is also recommended not to use the swab or suction method to collect unstimulated whole saliva because the swabbing action provides some degree of stimulation and thus increases variability [27]. A previous study found that saliva biomarkers such as DHEA, testosterone, estradiol and progesterone were observed to be statistically significant $(p<0.005)$ and, sIgA significantly decreased $(\mathrm{p}<0.005)$ in cotton-based collection methods than no-cotton methods, however, cotinine and cortisol were not affected, suggesting the collection method as a remarkable source of unsystematic error [30]. Furthermore, samples obtained by spitting contain more bacteria than those obtained by drooling, which can affect further analysis of saliva compounds [31]. The passive drooling method is considered to be a promising alternative for minimizing these potential sources of error. Moreover, large volumes of saliva can be collected in a short time using the passive drooling method [32].

\section{Sample storage}

If the analysis is to be performed immediately, specimens can be stored at room temperature (maximum 30-90 $\mathrm{min}$ ) [31]. However, the paper published by Thomadaki $\mathrm{K}$ et al., suggest that lowering the incubation temperature lowers the degradation rate of salivary proteome [33]. Thus, immediately after saliva collection, it is recommended to freeze the samples at or below $-20^{\circ} \mathrm{C}$. If a freezer is not available, specimens can be stored at $4{ }^{\circ} \mathrm{C}$ to prevent bacterial growth and further degradation of salivary molecules (no longer than 6 h) [31]. Specimens can also be stored at $-80{ }^{\circ} \mathrm{C}$ for several years with little or no degradation [31,34]. It is always best to aliquot and freeze the samples to avoid repeated freeze-thaw cycles. Other storage and specimen processing approaches, including snap-freezing in liquid nitrogen and the use of enzyme inhibitors, are explained in previous studies $[31,35]$. For RNA analysis, RNase inhibitor should be added in the supernatant fractions (not to pellet) before storing at $-80{ }^{\circ} \mathrm{C}$ [36]. However, recently discovered QIAzol method has shown an ability to isolate high yields of RNA without the requirement of an extra RNA stabilizer. By using this method, saliva samples can be stored successfully for more than 2 years at $-80{ }^{\circ} \mathrm{C}$ without adding RNase inhibitors [37].

\section{Does psychological stress make a change in salivary protein secretion?}

Various reports suggest that psychological stress induce salivary alpha-amylase and cortisol levels and these stressors may include public speaking, watching suspense movies, dental procedures, examinations, sports competition, doing adventures e.g., bungee jumping and so forth [38-41]. Moreover, salivary amylase level was observed to react more rapidly than cortisol during psychological stress, which could be a better indicator of stress [38]. However, stress during dental treatment showed significant changes in the salivary cortisol and sIgA levels than alpha-amylase [42]. During acute stress, salivary nitrate and nitrite are significantly increased which play a significant role in stress-induced gastric injury protection. This study was demonstrated in bungee jump-induced acute stress [43]. Another interesting study suggests the stress role in salivary secretion during sports competition where high mental alertness is required to face the opponent. During the study, the researchers found that the winners were having higher levels of salivary cortisol before the competition, indicating psychophysiological arousal and managed to control the stress during mid-competition with the indication of higher 
salivary flow rate and higher sIgA secretion [44]. A previous study revealed a significant elevation in salivary cortisol, which was observed in chronic (study and exam preparation) and acute (examination) situations of the learning behavior [45]. In addition, salivary and serum cortisol levels are influenced by various stressors including insomnia, depression, and fatigue. The fatigue led by insomnia or other factors may be influenced by circadian rhythms [46]. Salivary amylase has also been identified as a biomarker for sleep deprivation in Drosophila and humans. The mRNA levels of amylase increase steadily during waking conditions despite no changes in salivary volume total protein [47].

In case of premenstrual syndrome (PMS), women embrace psychosomatic changes, depression and breast pain during or before menstruation [48, 49]. The concentration of sIgA was found to be significantly elevated during the premenstrual or menstrual phase when compared with the postmenstrual phase. In contrast, the higher level of sIgA was observed more in women having dysmenorrhea as compared to women without dysmenorrhea. However, there was no correlation between PMS and cortisol level [49]. During Trier Social Stress Test (TSST), cystatin S, alpha-amylase and light chain IgA, glutathione S-transferase and PIP (prolactin-inducible protein) were observed to be higher after the test [50]. Furthermore, the level of salivary IL-6 was highly elevated (approximately $50 \%$ ) and lasted for $20 \mathrm{~min}$ in healthy young adults in response to the TSST [51]. The acute stress activates the HPA axis and SNS, producing high levels of cortisol and alpha-amylase [52]. Different profile of mood states (POMS) also makes a change in salivary cortisol and alpha-amylase [52]. In addition, researchers have also demonstrated the stressinduced cortisol elevation on strategic behavior during the beauty contest game [53]. Dynamic changes such as cortisol concentrations, intraoral $\mathrm{pH}$ and total protein concentration were observed to be influenced in public speaking-induced acute stress without altering salivary fluoride concentration [54].

Based on above reports, we can anticipate that the salivary flow and secretory proteins can get varied in the healthy individuals. These variations may be either from POMS e.g., depression, anger, fatigue or from adventurous or from any strategic behavior. So, during saliva collection, we need to confirm from healthy volunteers that they are free from these kinds of psychological stress, which directly affect the saliva volume or salivary proteins. We need to categorize in different groups or exclude such volunteers to limit statistical errors. Noncompliance-induced errors may significantly diminish the post-analysis results.

\section{Questionnaire}

Each participant should complete a questionnaire to provide information regarding their condition and severity. Moreover, history of certain diseases, age, and sex need to be recorded before the participant completes the questionnaire [55]. We categorized the questionnaire into different sections of socio-demographic information (Table 1), medical history (Table 2), tobacco and alcohol habits (Table 3), oral hygiene (Table 4), and other (e.g., sleeping and speaking disorders) (Table 5). The sections are shown below in tabulated form.

Each item should be answered as 'yes' or 'no.' If an individual answers 'yes,' the frequency and severity of the condition should be recorded. If a person experiences xerostomia, the response should be recorded on a 10 -point scale $(0=$ not dry to $10=$ very dry).

Table 1. Demographic features and personal information

\begin{tabular}{lll}
\hline Questionnaire & Response & References \\
\hline Gender & Male/Female/Other & {$[55,56]$} \\
Age & Adult to senior & {$[55,56]$} \\
Weight $(\mathrm{kg})$ & Kilograms $(\mathrm{kg})$ & {$[56]$} \\
Height $(\mathrm{cm})$ & & {$[56]$} \\
BMI $\left(\mathrm{kg} / \mathrm{m}^{2}\right)$ & Under/normal/over/obese & {$[56,57]$} \\
Education level & & {$[55]$} \\
Country of birth & & {$[55]$} \\
\hline
\end{tabular}

Table 2. Medical history

\begin{tabular}{|c|c|c|}
\hline Questionnaire & Response & References \\
\hline Do you have a systemic disease? & Yes/No & {$[58]$} \\
\hline Do you take medicines daily? & Yes/No & \\
\hline $\begin{array}{l}\text { If you are taking medications, what type of } \\
\text { medicines/drugs you are taking? }\end{array}$ & Type of drugs & {$[55,59,60]$} \\
\hline $\begin{array}{l}\text { For female volunteers, does your period occur } \\
\text { normally? }\end{array}$ & Yes/No & {$[61]$} \\
\hline $\begin{array}{l}\text { If your period is abnormal, when did your last } \\
\text { period occur? }\end{array}$ & Days & \\
\hline $\begin{array}{l}\text { Rate the stress (mental/physical) and anxiety } \\
\text { in your daily life. }\end{array}$ & $0-10$ points & {$[62]$} \\
\hline Have you ever had head or neck radiotherapy? & Yes/No & \\
\hline $\begin{array}{l}\text { Have you ever suffered from salivary gland } \\
\text { disorders? }\end{array}$ & Yes/No & {$[58]$} \\
\hline $\begin{array}{l}\text { Have you ever suffered from arthritis or any } \\
\text { other autoimmune disease? }\end{array}$ & Yes/No & [58] \\
\hline Do you have any allergies? & Yes/No & \\
\hline Do you have diabetes? & Yes/No & {$[63]$} \\
\hline
\end{tabular}

Table 3. Tobacco and alcohol habits

\begin{tabular}{lll}
\hline Questionnaire & Response & References \\
\hline $\begin{array}{l}\text { Do you smoke? } \\
\begin{array}{l}\text { If yes, how many cigarettes do you consume } \\
\text { per day? }\end{array}\end{array}$ & $\begin{array}{l}\text { Yes/No } \\
\text { Cigarettes/Day }\end{array}$ & {$[55,64]$} \\
$\begin{array}{l}\text { Do you use tobacco products such as tobacco } \\
\text { leaves or tobacco powder? }\end{array}$ & Yes/No & {$[64]$} \\
$\begin{array}{l}\text { Do you drink alcohol or other beverages (e.g., } \\
\text { carbonated drinks)? }\end{array}$ & $\begin{array}{l}\text { Yes/No } \\
\text { (Specify) }\end{array}$ & {$[55,65]$} \\
$\begin{array}{l}\text { If yes, what volume do you consume per day? } \\
\text { ml/day }\end{array}$ & {$[55]$}
\end{tabular}


Table 4. Oral hygiene

\begin{tabular}{lll}
\hline Questionnaire & Response & References \\
\hline Do you have an oral lesion(s) (e.g., sore/ulcer)? & Yes/No & {$[55,66]$} \\
Do you feel a burning sensation in the mouth? & Yes/No & {$[55,57]$} \\
Does your mouth feel dry? & Yes/No & {$[55,67,68]$} \\
Do you have halitosis? & Yes/No & {$[55]$} \\
Do you wear dentures? & Yes/No & {$[55,57]$} \\
Do you use toothpaste daily? & Yes/No & {$[55]$} \\
Do you use dental floss daily? & Yes/No & {$[55]$} \\
Do you use mouthwash daily? & Yes/No & {$[55]$} \\
\hline
\end{tabular}

Table 5. Other

\begin{tabular}{lll}
\hline Questionnaire & Response & References \\
\hline Does your mouth feel dry when eating a meal? & Yes/No & {$[60,67]$} \\
Do you have difficulty swallowing dry food? & Yes/No & {$[67,69]$} \\
Do you seem to have too little saliva in your mouth? & Yes/No & {$[60,67]$} \\
Do you drink water or juice frequently? & Yes/No & \\
If yes, what volume do you consume per day? & ml/day & \\
Do you experience difficulties while speaking? & Yes/No & {$[69]$} \\
Do you have sleep problems due to dryness? & Yes/No & {$[65,69]$} \\
Do you suck sweets or chew gum to relieve dry & Yes/No & {$[65,70]$} \\
mouth? & Yes/No & {$[65,70]$} \\
Does your facial skin feel dry? & Yes/No & {$[68,70]$} \\
Do your eyes feel dry? & Yes/No & {$[65,70]$} \\
Do your lips feel dry? & Yes/No & {$[70]$} \\
Does the inner part of your nose feel dry? & Yes/No & {$[63,71]$} \\
Does your throat feel dry? & &
\end{tabular}

\section{Inclusion criteria}

Participants should be selected based on the following criteria.

- Participants should be aged 18 years or older. Note: Individuals younger than 18 years might not understand the questionnaire, might not understand the consent form, might not correctly fill out the consent form, or might not follow the guidelines. Moreover, individuals aged 60 years or older should not participate in the study. Although these individuals might be otherwise healthy, the incidence of hyposalivation in older individuals is higher than in younger individuals [60].

- Participants should be able to read, complete, and sign the consent form.

- Participants should understand and answer the questionnaire.

- Volunteers should be disease-free, specifically with respect to the salivary glands and oral mucosa [68].

- Participants should not have dry mouth or dry eye sensations.

\section{Exclusion criteria}

- Participants who are less than 18 years of age.

- Participants who cannot read or understand the consent form.
- Individuals who answer 'yes' to the dryness-related question. These individuals are considered positive for xerostomia and cannot participate in the study.

- Pregnant women.

- Participants who complain of dry mouth or dry eyes [68].

- Patients with oral lesions or other contact sensitivity [66].

- Patients suffering from autoimmune diseases such as Sjogren's syndrome, rheumatoid arthritis, systemic lupus erythematosus, or progressive systemic sclerosis, since individuals with these autoimmune inflammatory diseases exhibit persistent xerostomia $[58,72]$.

- Individuals with acute or chronic use of medications known to cause oral dryness [66]. These include drugs such as anti-histamines, anti-psychotics, and anti-depressants [58, 59].

- Patients undergoing radiotherapy (mainly for head and neck cancer treatment).

- Individuals with chronic medical illness, if it is not well controlled.

- Individuals with HIV, hepatitis B, or hepatitis C infection.

\section{Sampling error and management}

The possibility of sampling error is highest during saliva collection and processing. Incorrect methods of saliva collection also result in sampling error [73]. The investigator should use questionnaire answers to select eligible volunteers. It is better to select the intermediate scoring population to minimize potential variations in salivary flow rate. Food and drinks should be restricted during saliva collection. However, in certain cases, food can be eaten up to $30 \mathrm{~min}$ [32] to $1 \mathrm{~h}$ before spitting [9]. The individual should rinse his/her mouth with deionized water and wait at least $10 \mathrm{~min}$ before providing a specimen [32]. Clear and comprehensible labeling is necessary for proper sample identification and handling. Permanent markers or bar-coded labels are highly recommended for long-term storage [34].

Before collection, the optimal sample collection technique (as mentioned in sections 3.3 and 3.5) should be carefully chosen based on age and the experiment of interest. Participants should be instructed precisely regarding the optimal placement and duration of the device or swab in order to ensure analyte measurement accuracy. The collected saliva should be free of contamination from particulate matter or other interfering substances [32]. Sample contamination can be prevented by wearing gloves 
and using clean collection materials [74]. After collection, the specimen should be stored or processed appropriately as described in section 3.6. Some salivary analytes such as dehydroepiandrosterone, estradiol, and progesterone are very sensitive to freeze-thawing, so multiple freeze-thaw cycles should be avoided [32].

Other influencing factors include age, sex distribution, and living environment. The duration and time-slot of sample collection have been shown to affect analyte concentration, mainly for stress markers such as cortisol, secretory immunoglobulin A, and chromogranin A [74]. Saliva collection from healthy volunteers is like an observational study, where the participants should be selected based on questionnaire responses, detailed histories, and complete clinical examinations, if applicable. The different aspects of compliance for saliva collection from healthy volunteers can all minimize sampling error. These aspects are summarized in Figure 1.

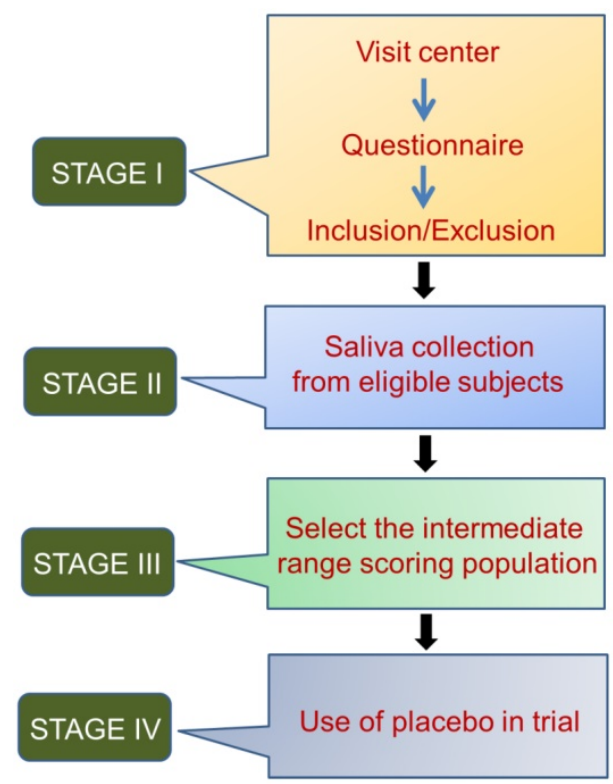

Figure 1. Four stages of saliva collection from healthy volunteers

To overcome sample-to-sample variation, the salivary output of each individual needs to be measured. Specifically, each individual should be classified as secreting a high, medium, or low volume of saliva. The salivary flow rate varies among healthy individuals [75]. This variation directly influences the total concentration and enzymatic activity of proteins such as salivary alpha amylase in healthy young individuals, even in the absence of a stressful stimulus [4]. Salivary flow rate, total salivary protein concentration, and saliva osmolality are potential markers of whole body hydration status and can fluctuate during acute dehydration [76]. Normal- ization factors (for example, creatinine concentration of urine samples) [77] for saliva samples have not yet been established; however, measurement of total protein concentration is consistently used to normalize the concentration of the salivary analytes, since various stimulations can affect the total protein concentration in saliva [78, 79]. According to a previous study, the increment in salivary flow rate actually decreased the total protein concentration of salivary samples [78]. However, in one study, the authors found that the protein concentration in saliva samples was not strongly associated with salivary volume, but was associated with salivary CRP concentration. This finding is thought to be important in the neonatal population where the variation of salivary volume is high [80].

Circadian and circannual rhythms also influence the unstimulated salivary flow rates [81, 82], in addition to sodium and potassium concentrations [81]. Therefore, to ensure that consistent results are obtained, individuals should be selected based on their salivary flow rate (not saliva volume). Only individuals whose saliva secretion is in the medium range should be included in the study. Moreover, the baseline specimen collection time should be set at approximately the same time every day for all individuals in order to minimize variability [82].

Another method for reducing sample variability is to try collecting samples on multiple days. Participants should be asked to collect the specimen on different days (e.g., for 5 days) at a specified time and under certain conditions (as mentioned in section 2). Specimens can be collected either at home or at a collection center. Total specimens are collected, and primary biomarkers such as salivary flow rate, total protein concentration, and salivary enzymes (e.g., alpha-amylase) are examined. This method helps determine the extent to which the participants adhered to the relevant guidelines [83]. Participants with good protocol adherence and who have had only minimum or no errors throughout the multiple-day collection period will be selected in further clinical trials as healthy volunteers (Figure 2). For any type of drug trial, the results must be compared between patients with disease and healthy individuals; this step is included in the next phase of the clinical trial.

\section{Discussion and conclusions}

We developed a strategic protocol for the collection of saliva from healthy volunteers. Various studies have examined the efficacy of interventions for treating xerostomia and other dryness-related complications. In clinical trials, statistical analyses are performed to compare results of healthy participants with those of patients. Proper collection of saliva from 
healthy volunteers is necessary to minimize sampling error. An optimized protocol for evaluating saliva samples from healthy individuals has not yet been developed, and the National Institutes of Health is still recruiting healthy volunteers for salivary evaluation [84]. Moreover, many studies of healthy volunteers have not included detailed questionnaires, thereby increasing the sampling error. Furthermore, inadequate questionnaires might not obtain sufficient information for selecting eligible individuals. We aimed to collect this information by adding a questionnaire that facilitates the determination of whether the healthy volunteers satisfy the inclusion or exclusion criteria. These questions can reduce the risk of inaccurate measurement of salivary analytes from healthy individuals (Tables 1-5).

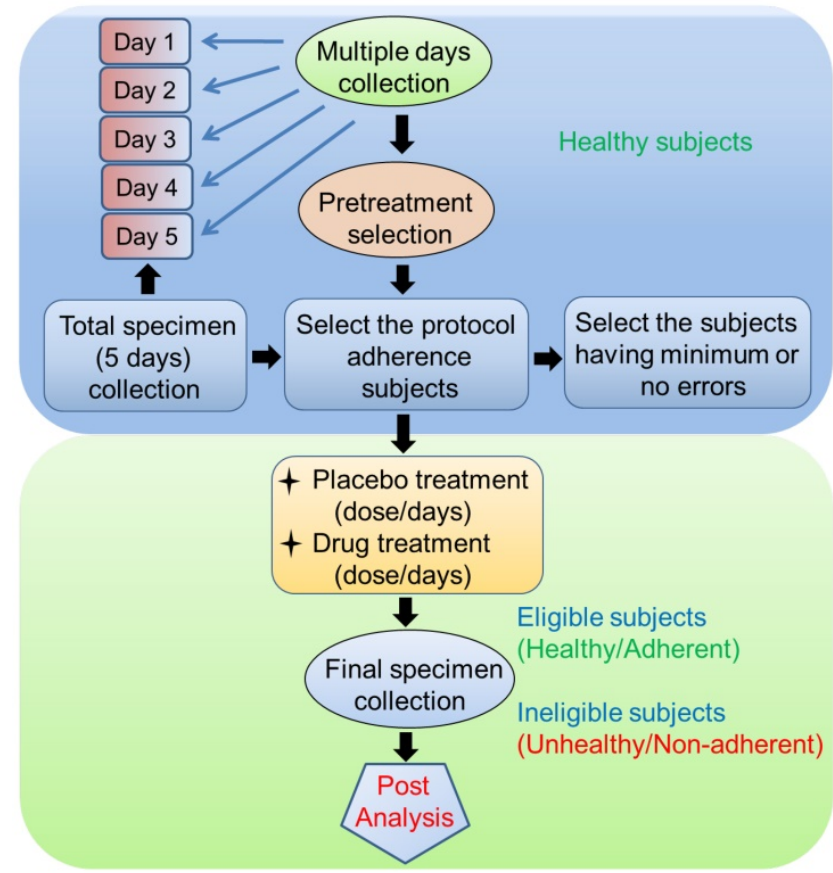

Figure 2. Specimen collection (saliva) process to minimize inter-individual variability

Saliva contamination from blood or other substances could interfere with post-collection immunoassays. Research participants who donate saliva should be aware of several factors. First, consumption of alcohol less than 12 hours before saliva collection could affect saliva composition. Similarly, the consumption of meals containing foods with high sugar, high acidity, and/or high caffeine could lower salivary $\mathrm{pH}$ and thus increase bacterial growth. Volunteers should also be screened for oral hygiene, oral injuries, and brushing habits. In addition, use of medications and nicotine should be documented [85].

Another factor responsible for sampling error is the collection device. As described in section 2, several methods and devices have been developed for saliva collection. In addition, the Muddler was developed recently [86]. This device can be used with both infants and adults and can effectively collect a constant volume of saliva. Furthermore, this device is very advantageous for stress-related and immunityrelated studies and other salivary biomarker analyses [86]. However, special attention should be paid to sample storage prior to analysis [87].

If saliva is handled wisely, salivary biomarkers such as enzymes and proteins (e.g., alpha-amylase) [4], stress proteins (e.g., GRP78) [3, 88] and HSP70 [89], infectious diseases (e.g., HIV), oral squamous cell carcinoma [90, 91], and CA125 markers of neoplasia [92] can be effectively assessed. Additionally, analytes such as hormones, steroids, antibodies, growth factors, cytokines, chemokines, nucleic acids, and proteins related to different systemic diseases, psychological research, autoimmune diseases, and oral diseases (caused by fungus, viruses, and bacteria) can be successfully implemented in diagnostic applications [87].

\section{Abbreviations}

CRP: C-reactive protein; Ig: Immunoglobulin; sIgA: Secretory immunoglobulin A; OSCC: Oral squamous cell carcinoma; AIDS: Acquired immune deficiency syndrome; $\mathrm{CD}$ : Cluster of differentiation; HPA: Hypothalamic-pituitary-adrenal; SNS: Sympathetic nervous system; M2BP: Mac-2 binding protein; MRP14: Myeloid-related protein 14; NF-kB: Nuclear factor-kappa B; IL: Interleukin; HPLC: High-performance liquid chromatography; ELISA: Enzyme-linked immunosorbent assay; LC/MS: Liquid chromatography-mass spectrometry; MALDI-TOF MS: Matrix-assisted laser desorption/ionization-time-offlight mass spectrometer; PCR: Polymerase chain reaction; GRP78: Glucose-regulated protein 78; HSP70: Heat shock protein 70.

\section{Acknowledgments}

This work was carried out with the support of the Cooperative Research Program for Agriculture Science \& Technology Development (Project No. PJ01158104 and PJ01389701), funded by the Rural Development Administration, Republic of Korea. This study was also supported by the Bio \& Medical Technology Development Program (NRF-2017M3A9 E4047243), funded by the Ministry of Science, ICT and Future Planning, Republic of Korea.

\section{Competing Interests}

The authors have declared that no competing interest exists. 


\section{References}

1. Javaid MA, Ahmed AS, Durand R, Tran SD. Saliva as a diagnostic tool for oral and systemic diseases. Journal of oral biology and craniofacial research. 2016; 6: 66-75.

2. Bhattarai KR, Lee SW, Kim SH, Kim HR, Chae HJ. Ixeris dentata extract regulates salivary secretion through the activation of aquaporin-5 and prevents diabetes-induced xerostomia. Journal of experimental pharmacology. 2017; 9: 81-91.

3. Bhattarai KR, Lee HY, Kim SH, Kim HR, Chae HJ. Ixeris dentata Extract Increases Salivary Secretion through the Regulation of Endoplasmic Reticulum Stress in a Diabetes-Induced Xerostomia Rat Model. International journal of molecular sciences. 2018; 19(4):1059.

4. Arhakis A, Karagiannis V, Kalfas S. Salivary alpha-amylase activity and salivary flow rate in young adults. The open dentistry journal. 2013; 7: 7-15.

5. Lukacs JR, Largaespada LL. Explaining sex differences in dental caries prevalence: saliva, hormones, and "life-history" etiologies. American journal of human biology : the official journal of the Human Biology Council. 2006; 18: 540-55.

6. Dawes C. Effects of diet on salivary secretion and composition. Journal of dental research. 1970; 49: 1263-73.

7. Sundus Ismail Al-Azzawi, Alia Mahmood Alwan, Salal RH. Influence of age and gender on salivary flow rate in completely edentulous patients. MDJ. 2013; 10: 64-8.

8. Mohamed R, Campbell JL, Cooper-White J, Dimeski G, Punyadeera C. The impact of saliva collection and processing methods on CRP, IgE, and Myoglobin immunoassays. Clinical and translational medicine. 2012; 1: 19 .

9. Beltzer EK, Fortunato CK, Guaderrama MM, Peckins MK, Garramone BM, Granger DA. Salivary flow and alpha-amylase: collection technique, duration, and oral fluid type. Physiology \& behavior. 2010; 101: 289-96.

10. Jenzano JW, Hogan SL, Lundblad RL. Factors influencing measurement of human salivary lysozyme in lysoplate and turbidimetric assays. Journal of clinical microbiology. 1986; 24: 963-7.

11. Castagnola M, Scarano E, Passali GC, Messana I, Cabras T, Iavarone F, et al. Salivary biomarkers and proteomics: future diagnostic and clinical utilities. Acta otorhinolaryngologica Italica : organo ufficiale della Societa italiana di otorinolaringologia e chirurgia cervico-facciale. 2017; 37: 94-101.

12. Al Kawas S, Rahim ZH, Ferguson DB. Potential uses of human salivary protein and peptide analysis in the diagnosis of disease. Archives of oral biology. 2012; 57: 1-9.

13. Sannam Khan R, Khurshid Z, Akhbar S, Faraz Moin S. Advances of Salivary Proteomics in Oral Squamous Cell Carcinoma (OSCC) Detection: An Update. Proteomes. 2016; 4(4):41.

14. Hu S, Arellano M, Boontheung P, Wang J, Zhou H, Jiang J, et al. Salivary proteomics for oral cancer biomarker discovery. Clinical cancer research : an official journal of the American Association for Cancer Research. 2008; 14: 6246-52.

15. Rhodus NL, Ho V, Miller CS, Myers S, Ondrey F. NF-kappaB dependent cytokine levels in saliva of patients with oral preneoplastic lesions and oral squamous cell carcinoma. Cancer detection and prevention. 2005; 29: 42-5.

16. Aziz S, Ahmed SS, Ali A, Khan FA, Zulfiqar G, Iqbal J, et al. Salivary Immunosuppressive Cytokines IL-10 and IL-13 Are Significantly Elevated in Oral Squamous Cell Carcinoma Patients. Cancer investigation. 2015; 33: 318-28.

17. Ryu OH, Atkinson JC, Hoehn GT, Illei GG, Hart TC. Identification of parotid salivary biomarkers in Sjogren's syndrome by surface-enhanced laser desorption/ionization time-of-flight mass spectrometry and two-dimensional difference gel electrophoresis. Rheumatology. 2006; 45: 1077-86.

18. Wormwood KL, Aslebagh R, Channaveerappa D, Dupree EJ, Borland MM, Ryan JP, et al. Salivary proteomics and biomarkers in neurology and psychiatry. Proteomics Clinical applications. 2015; 9: 899-906.

19. Nassar M, Hiraishi N, Islam MS, Otsuki M, Tagami J. Age-related changes in salivary biomarkers. Journal of Dental Sciences. 2014; 9: 85-90

20. Ben-Aryeh H, Shalev A, Szargel R, Laor A, Laufer D, Gutman D. The salivary flow rate and composition of whole and parotid resting and stimulated saliva in young and old healthy subjects. Biochemical medicine and metabolic biology. 1986; 36: 260-5.

21. Denny PC, Denny PA, Klauser DK, Hong SH, Navazesh M, Tabak LA. Age-related changes in mucins from human whole saliva. Journal of dental research. 1991; 70: 1320-7.

22. Inzitari R, Vento G, Capoluongo E, Boccacci S, Fanali C, Cabras T, et al. Proteomic analysis of salivary acidic proline-rich proteins in human preterm and at-term newborns. Journal of proteome research. 2007; 6: 1371-7.

23. Cabras T, Pisano E, Boi R, Olianas A, Manconi B, Inzitari R, et al. Age-dependent modifications of the human salivary secretory protein complex. Journal of proteome research. 2009; 8: 4126-34

24. Fenoll-Palomares C, Munoz Montagud JV, Sanchiz V, Herreros B, Hernandez $\mathrm{V}$, Minguez $\mathrm{M}$, et al. Unstimulated salivary flow rate, $\mathrm{pH}$ and buffer capacity of saliva in healthy volunteers. Revista espanola de enfermedades digestivas: organo oficial de la Sociedad Espanola de Patologia Digestiva. 2004; 96: 773-83.

25. Scott J. Age, sex and contralateral differences in the volumes of human submandibular salivary glands. Archives of oral biology. 1975; 20: 885-7.

26. Salimetrics. The Importance of Mouth Location During Saliva Collection. 1-7.

27. Navazesh M. Methods for collecting saliva. Annals of the New York Academy of Sciences. 1993; 694: 72-7.
28. Rantonen P. Salivary flow and composition in healthy and diseased adults. 2003.

29. Golatowski C, Salazar MG, Dhople VM, Hammer E, Kocher T, Jehmlich N, et al. Comparative evaluation of saliva collection methods for proteome analysis. Clinica chimica acta; international journal of clinical chemistry. 2013; 419: 42-6.

30. Shirtcliff EA, Granger DA, Schwartz E, Curran MJ. Use of salivary biomarkers in biobehavioral research: cotton-based sample collection methods can interfere with salivary immunoassay results. Psychoneuroendocrinology. 2001; 26: 165-73.

31. Chiappin S, Antonelli G, Gatti R, De Palo EF. Saliva specimen: a new laboratory tool for diagnostic and basic investigation. Clinica chimica acta; international journal of clinical chemistry. 2007; 383: 30-40.

32. Granger DA, Johnson SB, Szanton SL, Out D, Schumann LL. Incorporating salivary biomarkers into nursing research: an overview and review of best practices. Biological research for nursing. 2012; 14: 347-56.

33. Thomadaki K, Helmerhorst EJ, Tian N, Sun X, Siqueira WL, Walt DR, et al. Whole-saliva proteolysis and its impact on salivary diagnostics. Journal of dental research. 2011; 90: 1325-30.

34. Salimetrics L, SalivaBio L. Saliva Collection and Handling Advice. Salimetrics. 2015; 3(3rd Edition): 1-15.

35. Nurkka A, Obiero J, Kayhty H, Scott JA. Effects of sample collection and storage methods on antipneumococcal immunoglobulin A in saliva. Clinical and diagnostic laboratory immunology. 2003; 10: 357-61.

36. Henson BS, Wong DT. Collection, storage, and processing of saliva samples for downstream molecular applications. Methods in molecular biology. 2010; 666: 21-30

37. Pandit P, Cooper-White J, Punyadeera C. High-yield RNA-extraction method for saliva. Clinical chemistry. 2013; 59: 1118-22.

38. Takai N, Yamaguchi M, Aragaki T, Eto K, Uchihashi K, Nishikawa Y. Effect of psychological stress on the salivary cortisol and amylase levels in healthy young adults. Archives of oral biology. 2004; 49: 963-8.

39. Nejtek VA. High and low emotion events influence emotional stress perceptions and are associated with salivary cortisol response changes in a consecutive stress paradigm. Psychoneuroendocrinology. 2002; 27: 337-52.

40. Hennig J, Laschefski U, Opper C. Biopsychological changes after bungee jumping: beta-endorphin immunoreactivity as a mediator of euphoria? Neuropsychobiology. 1994; 29: 28-32.

41. van den Bos $\mathrm{E}$, de Rooij M, Miers AC, Bokhorst CL, Westenberg PM. Adolescents' increasing stress response to social evaluation: pubertal effects on cortisol and alpha-amylase during public speaking. Child development. 2014; 85: 220-36.

42. Ohura K, Nozaki T, Shinohara M, Daito K, Sonomoto M, Daito M. Utility of salivary biomarker for stress induced by dental treatment. Japanese Dental Science Review. 2012; 48: 14-7.

43. Jin L, Qin L, Xia D, Liu X, Fan Z, Zhang C, et al. Active secretion and protective effect of salivary nitrate against stress in human volunteers and rats. Free radical biology \& medicine. 2013; 57: 61-7.

44. Papacosta E, Nassis GP, Gleeson M. Salivary hormones and anxiety in winners and losers of an international judo competition. Journal of sports sciences. 2016; 34: 1281-7.

45. Gonzalez-Cabrera J, Fernandez-Prada M, Iribar-Ibabe C, Peinado JM. Acute and chronic stress increase salivary cortisol: a study in the real-life setting of a national examination undertaken by medical graduates. Stress. 2014; 17: 149-56.

46. Michael DJ, Valle B, Cox J, Kalns JE, Fogt DL. Salivary biomarkers of physical fatigue as markers of sleep deprivation. Journal of clinical sleep medicine : JCSM : official publication of the American Academy of Sleep Medicine. 2013; 9: 1325-31.

47. Seugnet L, Boero J, Gottschalk L, Duntley SP, Shaw PJ. Identification of a biomarker for sleep drive in flies and humans. Proceedings of the National Academy of Sciences of the United States of America. 2006; 103: 19913-8.

48. Craner JR, Sigmon ST, Martinson AA, McGillicuddy ML. Premenstrual disorders and rumination. Journal of clinical psychology. 2014; 70: 32-47.

49. Watanabe K, Shirakawa T. Characteristics of Perceived Stress and Salivary Levels of Secretory Immunoglobulin A and Cortisol in Japanese Women With Premenstrual Syndrome. Nursing and midwifery studies. 2015; 4: e24795.

50. Trueba AF, Mizrachi D, Auchus RJ, Vogel PD, Ritz T. Effects of psychosocial stress on the pattern of salivary protein release. Physiology \& behavior. 2012; 105: 841-9.

51. Izawa S, Sugaya N, Kimura K, Ogawa N, Yamada KC, Shirotsuki K, et al. An increase in salivary interleukin-6 level following acute psychosocial stress and its biological correlates in healthy young adults. Biological psychology. 2013; 94: 249-54

52. Giles GE, Mahoney CR, Brunye TT, Taylor HA, Kanarek RB. Stress effects on mood, HPA axis, and autonomic response: comparison of three psychosocial stress paradigms. PloS one. 2014; 9: e113618.

53. Leder J, Hausser JA, Mojzisch A. Stress and strategic decision-making in the beauty contest game. Psychoneuroendocrinology. 2013; 38: 1503-11.

54. Naumova EA, Sandulescu T, Bochnig C, Al Khatib P, Lee WK, Zimmer S, et al. Dynamic changes in saliva after acute mental stress. Scientific reports. 2014; 4: 4884 .

55. Villa A, Abati S. Risk factors and symptoms associated with xerostomia: a cross-sectional study. Australian dental journal. 2011; 56: 290-5. 
56. Sawair FA, Ryalat S, Shayyab M, Saku T. The unstimulated salivary flow rate in a jordanian healthy adult population. Journal of clinical medicine research. 2009; 1: 219-25.

57. Villa A, Polimeni A, Strohmenger L, Cicciu D, Gherlone E, Abati S. Dental patients' self-reports of xerostomia and associated risk factors. Journal of the American Dental Association. 2011; 142: 811-6.

58. Mortazavi H, Baharvand M, Movahhedian A, Mohammadi M, Khodadoustan A. Xerostomia due to systemic disease: a review of 20 conditions and mechanisms. Annals of medical and health sciences research. 2014; 4: 503-10.

59. Daniels TE. Evaluation, differential diagnosis, and treatment of xerostomia. The Journal of rheumatology Supplement. 2000; 61: 6-10.

60. Gupta A, Epstein JB, Sroussi H. Hyposalivation in elderly patients. Journal. 2006; 72: 841-6.

61. Saluja P, Shetty V, Dave A, Arora M, Hans V, Madan A. Comparative Evaluation of the Effect of Menstruation, Pregnancy and Menopause on Salivary Flow Rate, $\mathrm{pH}$ and Gustatory Function. Journal of clinical and diagnostic research : JCDR. 2014; 8: ZC81-5.

62. Veerabhadrappa SK, Chandrappa PR, Patil S, Roodmal SY, Kumarswamy A, Chappi MK. Evaluation of Xerostomia in Different Psychological Disorders: An Observational Study. Journal of clinical and diagnostic research : JCDR. 2016; 10: ZC24-ZC7.

63. Sreebny LM, Valdini A, Yu A. Xerostomia. Part II: Relationship to nonoral symptoms, drugs, and diseases. Oral surgery, oral medicine, and oral pathology. 1989; 68: 419-27.

64. Rad M, Kakoie S, Niliye Brojeni F, Pourdamghan N. Effect of Long-term Smoking on Whole-mouth Salivary Flow Rate and Oral Health. Journal of dental research, dental clinics, dental prospects. 2010; 4: 110-4.

65. Thomson WM, Chalmers JM, Spencer AJ, Slade GD. Medication and dry mouth: findings from a cohort study of older people. Journal of public health dentistry. 2000; 60: 12-20.

66. Poon R, Su N, Ching V, Darling M, Grushka M. Reduction in unstimulated salivary flow rate in burning mouth syndrome. British dental journal. 2014; 217: E14.

67. Farsi NM. Signs of oral dryness in relation to salivary flow rate, $\mathrm{pH}$, buffering capacity and dry mouth complaints. BMC oral health. 2007; 7: 15.

68. FenolI-Palomares C, Munoz-Montagud J, Sanchiz V, Herreros B, Hernández $\mathrm{V}$, Minguez $\mathrm{M}$, et al. Unstimulated salivary flow rate, $\mathrm{pH}$ and buffer capacity of saliva in healthy volunteers. Revista espanola de enfermedades digestivas. 2004; 96: 773-83.

69. Alajbeg I, Falcao DP, Tran SD, Martin-Granizo R, Lafaurie GI, Matranga D, et al. Intraoral electrostimulator for xerostomia relief: a long-term, multicenter, open-label, uncontrolled, clinical trial. Oral surgery, oral medicine, oral pathology and oral radiology. 2012; 113: 773-81.

70. van der Putten GJ, Brand HS, Schols JM, de Baat C. The diagnostic suitability of a xerostomia questionnaire and the association between xerostomia, hyposalivation and medication use in a group of nursing home residents. Clinical oral investigations. 2011; 15: 185-92.

71. Ship JA. Diagnosing, managing, and preventing salivary gland disorders. Oral diseases. 2002; 8: 77-89.

72. Bhattarai KR, Junjappa R, Handigund M, Kim H-R, Chae H-J. The imprint of salivary secretion in autoimmune disorders and related pathological conditions. Autoimmunity Reviews. 2018; 17: 376-390.

73. Erasmus CE, Van Hulst K, Van Den Hoogen FJ, Van Limbeek J, Roeleveld N, Veerman EC, et al. Thickened saliva after effective management of drooling with botulinum toxin A. Developmental medicine and child neurology. 2010; 52: e114-8.

74. Lensen CM, Moons CP, Diederich C. Saliva sampling in dogs: How to select the most appropriate procedure for your study. Journal of Veterinary Behavior: Clinical Applications and Research. 2015; 10: 504-12.

75. Ghezzi EM, Lange LA, Ship JA. Determination of variation of stimulated salivary flow rates. Journal of dental research. 2000; 79: 1874-8.

76. Walsh NP, Montague JC, Callow N, Rowlands AV. Saliva flow rate, total protein concentration and osmolality as potential markers of whole body hydration status during progressive acute dehydration in humans. Archives of oral biology. 2004; 49: 149-54.

77. Wagner BD, Accurso FJ, Laguna TA. The applicability of urinary creatinine as a method of specimen normalization in the cystic fibrosis population. Journal of cystic fibrosis : official journal of the European Cystic Fibrosis Society. 2010; 9: $212-6$

78. Goodson JM, Kantarci A, Hartman ML, Denis GV, Stephens D, Hasturk H, et al. Metabolic disease risk in children by salivary biomarker analysis. PloS one. 2014; 9: e98799.

79. Lee JY, Chung JW, Kim YK, Chung SC, Kho HS. Comparison of the composition of oral mucosal residual saliva with whole saliva. Oral diseases. 2007; 13: 550-4.

80. Iyengar A, Paulus JK, Gerlanc DJ, Maron JL. Detection and potential utility of C-reactive protein in saliva of neonates. Frontiers in pediatrics. 2014; 2: 131

81. Dawes C. Circadian rhythms in the flow rate and composition of unstimulated and stimulated human submandibular saliva. The Journal of physiology. 1975; 244: 535-48.

82. Swenson LI. Progress in Tumor Marker Research. 2007; 2007:17-41.

83. Halpern CT, Whitsel EA, Wagner B, Harris KM. Challenges of measuring diurnal cortisol concentrations in a large population-based field study. Psychoneuroendocrinology. 2012; 37: 499-508.

84. ClinicalTrials.gov. Salivary Evaluation in Healthy Volunteers. 2017.
85. Salimetrics L. Saliva Collection and Handling Advice. 2011: 2(2nd Edition): 1-11.

86. Takagi K, Ishikura Y, Hiramatsu M, Nakamura K, Degawa M. Development of a saliva collection device for use in the field. Clinica chimica acta; international journal of clinical chemistry. 2013; 425: 181-5.

87. Malamud D. Saliva as a diagnostic fluid. Dental clinics of North America. 2011; 55: 159-78

88. Giusti L, Baldini C, Ciregia F, Giannaccini G, Giacomelli C, De Feo F, et al. Is GRP78/BiP a potential salivary biomarker in patients with rheumatoid arthritis? Proteomics Clinical applications. 2010; 4: 315-24.

89. Fabian TK, Fejerdy P, Nguyen MT, Soti C, Csermely P. Potential immunological functions of salivary $\mathrm{Hsp70}$ in mucosal and periodontal defense mechanisms. Archivum immunologiae et therapiae experimentalis. 2007; 55: 91-8.

90. Sherman GG, Lilian RR, Coovadia AH. Oral fluid tests for screening of human immunodeficiency virus-exposed infants. The Pediatric infectious disease journal. 2010; 29: 169-72.

91. Tiwari M. Science behind human saliva. Journal of natural science, biology, and medicine. 2011; 2: 53-8

92. Agha-Hosseini F, Mirzaii-Dizgah I, Rahimi A, Seilanian-Toosi M. Correlation of serum and salivary CA125 levels in patients with breast cancer. The journal of contemporary dental practice. 2009; 10: E001-8. 